\title{
Ideologia e intertextualidade: signos náuticos na representação de Portugal em Gil Vicente e Sttau Monteiro
}

\author{
Ideology and intertextuality: the representation of Portugal \\ in Gil Vicente and Sttau Monteiro
}

\author{
JAIME DOS REIS SANT'ANNA \\ Universidade Estadual de Londrina - Londrina - Paraná - Brasil
}

\begin{abstract}
Resumo: O objetivo desse artigo é analisar o Auto da barca do motor fora da borda (1966), de Luís de Sttau Monteiro, a partir do diálogo intertextual que ele trava com o Auto da barca do inferno (1517), de Gil Vicente. Signos cênicos náuticos, tais como a barca e o cruzeiro, são utilizados pelos autores como cronotopos literário para representar Portugal em momentos históricos distintos; todavia, em ambas as situações, predomina a exclusão social dos que fazem mover a nação.
\end{abstract}

Palavras-chave: Gil Vicente; Intertextualidade; Sttau Monteiro

\begin{abstract}
The objective is compare the Auto da barca do motor fora da borda (1966), by Luís de Sttau Monteiro, with Auto da barca do inferno (1517), by Gil Vicente. The authors use boat and cruise to represent Portugal in two historic moments. However, in both instances, people who work for thrive the society cannot participate in its progress.
\end{abstract}

Keywords: Gil Vicente; Intertextuality; Sttau Monteiro

\section{O porto de partida}

O Auto da barca do motor fora da borda, de 1966, é um intertexto do português Luís de Sttau Monteiro, que dialoga com o prototexto de Gil Vicente Auto da Barca do Inferno, de 1517. Em ambas as peças encontramos signos cênicos náuticos, como a barca e o cruzeiro moderno, que representam a sociedade portuguesa do século XVI e do século XX, respectivamente, refletindo elementos carnavalescos, sobretudo a subversão da ordem e a inversão das convenções. Para Bakhtin, enquanto rito e festividade, o carnaval está enraizado na sociedade primitiva e se materializa na produção literária e, de modo particular, na literatura dramática, cuja origem são as celebrações dionisíacas: uma vida desviada da sua ordem habitual; em certo sentido, uma vida às avessas, um mundo invertido (BAKHTIN, 1997, p. 123).

O objetivo desse artigo é estudar os signos cênicos utilizados no Auto da Barca do Inferno (doravante ABI) e no Auto da barca do motor fora da borda (doravante $A B M F B$ ), buscando a representação ideológica que seus autores fazem de Portugal, como forma de criticar a sociedade portuguesa em que viveram. A configuração carnavalesca de ambas as peças descortina o uso recorrente da linguagem de formas concreto-sensoriais simbólicas, a qual não pode ser traduzida com plenitude e adequação somente por meio da linguagem verbal. Daí, a recorrência com que, segundo Bakhtin, ela se expressa através da linguagem não-verbal dos signos e, no caso específico da literatura dramática, dos signos cênicos (BAKHTIN, 1997, p. 122).

Para Bakhtin, "todo signo é ideológico e carrega em si o valor de representação do conjunto da vida social" (BAKHTIN, 1997, p. 31,33). A partir dessa assertiva, demonstraremos em que medida o $A B I$, como texto de partida, e o $A B M F B$, como texto de chegada, lançam mão de alguns símbolos recorrentes para exprimir de maneira diversificada a representação social: barcas e cruzeiro moderno se apresentam como símbolos teatrais de uma linguagem não-verbal, presentes quer como cronotopos do entrecho, quer como espaço cênico de representação do mise-en-scène.

Em outros termos, no $A B I$, Gil Vicente representa a sociedade portuguesa, cujo comportamento parasitário receberá o devido castigo, mesmo que restrito ao âmbito transcendental; no $A B M F B$, o pessimismo crasso da geração de Sttau Monteiro não dá lugar a qualquer espécie de utopia, uma vez que a crítica à política de Antônio de 
Oliveira Salazar se frustra dentro de um sistema castrador dos sonhos utópicos. Para o autor contemporâneo, somente a eliminação das chamadas forças anônimas que fomentam as ideologias dominantes, singularmente representadas pelo Banqueiro/Onzeneiro, pode romper com o fenômeno da alienação em que se encontra Portugal. Tirar a nação do estado social de letargia, eliminar as forças capitalistas do sistema financeiro (o Banqueiro) que se sustentam em sua própria estagnação, são pressupostos que se colocam para aquém do processo utópico. Antes do estado de conscientização desta realidade, vale tão somente a denúncia sttaumonteirista, refletida na fala mais de uma vez repetida pelo Arrais: "Barca parada não serve para navegar" (MONTEIRO, 1970, p. 22) ${ }^{1}$.

No caso do $A B M F B$, os recursos metateatrais abrem aos espectadores a oportunidade de adentrar nos processos de produção do espetáculo. Por tratar-se de um texto metateatral (uma peça dentro de outra), as noções de espaço diversificam inúmeras possibilidades que se somam à rica simbologia de representações espaciais proposta pelo Teatro de Gil Vicente, revelando as intenções dos autores, ainda que mascaradas por símbolos teatrais recorrentes. A primeira rubrica do $A B M F B$ registra que do palco o ambiente de feira e de festa deverá ultrapassar o fosso da orquestra e contagiar os espectadores, mesclando os espaços cenográficos e dramáticos, de tal maneira a incorporar os signos feira e festa à sugestão de carnavalização.

A partir da sugestão presente na fala do Arrais Contemporâneo - "mudou o mundo [...], mudaram as barcas" -, Sttau Monteiro coteja as duas barcas que refletem dois países diferentes: Portugal do século XVI e Portugal do século XX. Bakhtin propôs que o estudo dialógico levasse em conta um complexo sistema teórico a que chamou de cronotopos, definido pelo linguista como uma interligação fundamental das relações temporais e espaciais, artisticamente assimiladas em Literatura. Para ele, ocorre uma fusão dos indícios espaciais e temporais num todo compreensivo e concreto, em que o princípio condutor do cronotopos é o tempo (BAKHTIN, 1998, p. 211).

Gil Vicente é um autor que se insere em um período de transição entre o fim da Idade Média e o início do Renascimento. Qualquer estudo que lance luz sobre sua obra projetará a sombra de um minotauro: a cabeça medieval em um corpo humanista, ou vice-versa. A pluralidade que decore deste hibridismo é propícia

\footnotetext{
1 A partir desse espaço, tendo em vista a profusão das referências ao $A B I$, de Gil Vicente, e ao $A B M F B$, de Sttau Monteiro, restringiremos as indicações bibliográficas apenas às páginas das edições de ambas as peças analisadas: VICENTE, Gil. Obras de Gil Vicente. Porto: Lello \& Irmãos Editores, 1965; MONTEIRO, Luís de Sttau. Auto da barca do motor fora da barca. Lisboa: Ática, 1970.
}

ao diálogo intertextual. $\mathrm{O}$ eixo em torno do qual se desenvolve a fábula do $A B I$, qual seja, a condenação ou absolvição dos estereótipos da sociedade portuguesa do século XVI, estabelece a cronotopia com que Sttau Monteiro interpretará a estrutura social portuguesa do século XX. Nessa direção, o signo mais sugestivo para sedimentar a ideia de movimento histórico é a embarcação. Em ambas as peças, as barcas revelam o estabelecimento cronotópico vicentino e a estreita relação com o cronotopos sttaumonteirista, apontando o que Todorov chamou de "a organização do mundo através do tempo e do espaço", categorias fundamentais do imaginário social (apud MACHADO, 1995, p. 251).

\section{Novos tempos, velhos tempos: Portugal na balança do tempo}

Irene Machado, escrevendo acerca da prosaica dialógica de Mikhail Bakhtin, mostra como ele concebeu o dialogismo como a ciência das relações e da diversidade, na qual vincula a análise estética às novas formas de compreensão do tempo e do espaço, pois há uma relatividade na percepção única, porque entre a mente que percebe e a coisa percebida há uma diversidade de focalizações (MACHADO, 1995, p. 258). Dessa forma, o momento histórico vicentino dialoga com o momento histórico sttaumonteirista, bem como cada personagem, cenário, situação social, valor moral, fala, etc., tornandose um diálogo referencial.

Em o $A B M F B$, Sttau Monteiro cria um metateatro, a partir dos conflitos gerados pelo encontro de duas gerações de atores: o grupo de atores que encena o $A B I$ numa interpretação atual e o grupo de atores da época quinhentista. Se no Teatro, como afirma Octavio Paz, a sociedade dialoga consigo mesma, então temos na peça de Monteiro um duplo diálogo: o dos estereótipos da sociedade vicentina com os respectivos estereótipos da sociedade atual; e o dos atores que representaram os estereótipos vicentinos no século XVI com seus colegas atores do século XX. Essa confluência cria o acréscimo de cada personagem desdobrada a partir de si mesma, uma vez que passam a conviver no espaço cenográfico, tanto o tipo popular vicentino, quanto o ator que o representou no século XVI; tanto a personagem contemporânea, quanto $\mathrm{o}$ ator que vai representá-la no presente.

A proposta sttaumonteirista estabelece um diálogo da sociedade consigo mesma, mas que a conscientize de que sua maior angústia não provém do confronto entre a riqueza da nação do século XVI com a pobreza do século XX, mas da constatação de que a estrutura de exclusão social que mantinha a pobreza, mesmo num momento histórico de prosperidade econômica, como foi o período manuelino de Gil Vicente, permanece pouco 
alterada no século XX. O cronotopos de sua peça constrói a crítica social, através de uma rede de signos teatrais ideologicamente carnavalizados, a fim de denunciar o quadro de exclusão social em que as personagens foram lançadas: na borda da sociedade.

\section{A Barca tradicional da moralização: o Diabo Barqueiro}

Em o $A B I$, ainda que as indicações de rubrica apontem que tenha sido encenada no espaço físico da câmara dos interiores do palácio real, onde foi apresentada para consolação da Rainha Dona Maria, estando enferma do mal de que veio a falecer, o espaço cênico dicotômico das barcas do Anjo e do Diabo trata do conjunto da sociedade portuguesa refletida nos estereótipos que transitam por ambas as embarcações.

A peça vicentina faz parte da chamada trilogia das barcas, que inclui o Auto da barca do purgatório (1518) e o Auto da barca da glória (1519). Mesmo que possamos ver nelas um sentido sobrenatural, evidenciando a cosmovisão soteriológica apresentada pela Igreja, parece haver uma preocupação com uma espécie de hierarquia dos viajantes das três embarcações. Enquanto na Barca da Glória perpassa a elite destinada às recompensas celestiais - conde, duque, rei, imperador, bispo, arcebispo, cardeal, papa, teólogos -, na do Inferno e na do Purgatório desfilam os representantes da sociedade lusitana do século XVI: fidalgo, onzeneiro, parvo, sapateiro, frade, alcoviteira, judeu, corregedor, procurador, criminoso, pastor, lavrador, regateira, cavaleiros.

Em ambos grupos retratados nos três Autos, as barcas representam, numa esfera mais ampla, a totalidade da nação portuguesa do século XVI, composta de elite e plebe. Porém, os da barca para o inferno representam o conjunto da sociedade portuguesa, refletindo a exclusão de uma parcela considerável, devido às diferenças sociais.

A Barca do Inferno é capitaneada pelo Diabo, que determina a obrigação de seus ocupantes de remar, como forma de castigo. Remar, aqui, simboliza uma alusão subreptícia à sociedade ociosa e parasitária, cuja ação conota o trabalho como paradoxal castigo aos parasitas sociais. Ao Fidalgo, o Diabo determina: "Tomareis hum par de remos,/Veremos como remai". (p. 225); ao Onzeneiro: "Entra, entra, e remarás./Não percamos mais maré" (p. 228); ao Frade: "Não façamos mais detença;/Embarcae, e partiremos;/Tomareis um par de remos". (p. 233); à Alcoviteira Brízida Vaz: "Entrae vós, e remareis”. (p. 236); ao Corregedor: "Sacto Descorregedor,/Embarcae, e remaremos/[...]/Ita, ita, dae ca a mão,/Remareis um remo destes". (p. 240); ao Procurador, redarguindo sua interpelação (Que diz esse Arrais? Que diz?): "Que sereis bom remador./Entrae, bacharel doutor, E ireis dando á bomba". (p. 242). Nem mesmo o Enforcado, executado pelo poder temporal, mas absolvido pelo sacerdote, recebe do Diabo outro tratamento: "Entra ca, e remarás/ Até ás portas do Inferno" (p. 244).

As admoestações do Diabo contra os membros da sociedade portuguesa dos Quinhentos tornam-no, paradoxalmente, o elemento admonitório, responsável pelo papel moralizante na dramatização. Este aspecto será essencial para a apropriação sttaumonteirista da fábula vicentina para ironicamente criticar o regime capitalista do século XX que também impõe exclusão social: nas mãos do Banqueiro/Onzeneiro, ela torna dispensável a figura do Diabo.

Também os acessórios que as personagens carregam para a barca têm valor simbólico, todos como registros metafóricos de seus vícios e que lhes são imputados como causa da condenação. Podemos alistar a cadeira e o pajem como figuras do ócio do Fidalgo; as ferramentas do Sapateiro como apego aos bens terrenos; o bode às costas do Judeu como indicativo das culpas expiatórias; o bolsão do Onzeneiro como marca da usura dos agiotas e o acúmulo de dinheiro; as armas de espadachim e a concubina do Frade como a secularização do sacerdócio decadente; os papéis do Corregedor como instrumentos de manipulação da justiça; e os objetos de luxúria de Brízida Vaz como instrumentos de incentivo à luxúria.

Entretanto, ainda que reconheçamos esta teleologia vicentina, mais significativo é registrar que são idiossincrasias do espírito parasitário com que estas personagens exploram a população produtiva de Portugal. Ou seja, o ócio do Fidalgo exige a exploração do pajem que carrega sua cadeira; as armas de espadachim são instrumentos de opressão aos fiéis pelo poder secular da Igreja Romana; os papéis do Corregedor usurpam da população o direito à justiça; o bolsão do Onzeneiro cresce na proporção em que mais endividados carecem de sua agiotagem; o apego aos bens materiais do Sapateiro subentende que o acúmulo de dinheiro de um requer a perda de muitos; etc.

\section{O barco moderno da exclusão: o Barqueiro Banqueiro}

No $A B M F B$, o signo da barca é acrescido de um novo elemento: a barca possui um motor. De início, ressurge a metáfora da barca para representar um Portugal naturalmente vocacionado para as grandes navegações. Signo de Portugal, a nova barca, porém, possui um signo de signo - o motor moderno -, representando os novos tempos de modernidade e industrialização, e sugerindo a inserção do país na nova era capitalista. Na perspectiva burguesa, em cuja política econômica Portugal luta por introduzir-se, o motor representa os avanços da sociedade 
industrial, onde a máquina a motor substitui a força humana em favor da qualidade de vida do homem. Os anos 1960 em que a peça foi escrita, revelam um país que precisava de modernização para fixar-se no cenário de transformações que marcam a Europa depois da Guerra; chegou o tempo de Portugal inserir-se numa Europa da qual até então fora excluído. Nesse contexto, o juízo sttaumonteirista é irônico: à pergunta do Arrais Vicentino (“E aonde ruma a vossa barca?"), o Arrais Contemporâneo avalia: "Não anda - ruma à deriva!" (p. 12).

Os dados econômicos e sociais desse período permitem avaliar que, de fato, o país rumava à deriva. A emigração e as guerras coloniais esvaziaram o país; a diminuição real dos salários gerou forte carestia; a mortalidade infantil era a mais alta da Europa; o déficit da balança comercial aumentava a dependência econômica das colônias, exatamente no momento em que o governo de Salazar sofria o isolamento internacional por causa das guerras de África. Diante deste quadro, deve-se considerar o crescente descontentamento da burguesia monopolista e o surgimento de uma oposição militar (PASCHKES, 1985, p. 76). No $A B M F B$, tal condição social é assistida inerte pelo representante do passado glorioso, como que tomado por uma surpresa paralisante: "O Arrais Vicentino, mesmo depois do pano ter subido, permanece como que em êxtase, voltado para o público... De pé, em cima do barco, imóveis como estátuas, os seguintes personagens..." (p. 13).

$\mathrm{O}$ barco parece ser a grande personagem de $A B M F B$, cuja presença muda centraliza o espaço cenográfico da peça, conforme as rubricas das primeiras cenas. A sua apresentação em duas etapas, através de uma iluminação gradual, realça a importância cênica que estabelece os contrastes que evidenciam o passado glorioso de Portugal e o seu declínio presente: num primeiro momento, "no centro do palco, em contraluz e colocado sobre estacas, um barco moderno - talvez um meio-cruzeiro - com um motor fora da borda; depois, o barco deixa gradualmente de estar em contraluz para surgir intensamente iluminado" (p. 13). O recurso realça uma dupla reação das personagens: a princípio, o Arrais Vicentino mostra-se alegre, batendo palmas (p. 12); os atores que representaram as personagens vicentinas vêm muito alegres (p. 12) e todos dançam alegremente e conversam uns com os outros (p. 13). Eles entram em cena, trazendo pães, odres de vinho e cestos de frutas (p. 12). Signos da fartura que caracterizava o Portugal do século XVI, tais elementos aprimoram ainda mais a reação entusiástica diante do país próspero metaforizado na barca.

A seguir, iluminado em contraluz, o barco cede momentaneamente a preeminência da cena para o quadro estático das mesmas personagens que esses atores representaram no passado, agora numa versão atualizada, cuja marca é a postura heráldica, pois elas estão "de pé, em cima do barco, imóveis como estátuas": um banqueiro respeitável, vestido a rigor; um burguês, imitando o banqueiro; um corregedor idoso e grave; uma mulher dos seus 50 anos, muito pintada, com um caso de vison; um industrial que imita o banqueiro e o burguês; um padre que imita o banqueiro, o burguês e o industrial (p. 13).

O Arrais mantém a alegria e o entusiasmo anteriores, convidando o público a participar da encenação de um genuíno auto de Gil Vicente. Há um paradoxo na cena: a "quebra da quarta-parede", caracterizada pelo contato direto com o público, ao mesmo tempo em que é um recurso para manter a racionalidade do público diante da encenação, se torna uma tentativa ineficiente de envolver emocionalmente a audiência em uma falsa empolgação: "Arrais Vicentino (Muito alegre, para o público): A barca de Mestre Gil volta hoje a navegar!" (p. 12). A segunda reação diante da barca se configura a partir do momento em que o barco deixa gradualmente de estar em contraluz para surgir intensamente iluminado. Os atores vicentinos olham-no com medo e calam-se (p. 13). O não reconhecimento daquele antigo signo da sociedade portuguesa converte a atitude do Arrais Vicentino em estupefação: "Barca do demo, do demo e não de mestre Gil!"” (p. 13). Estabelece-se o contraste de signos cênicos: barca e quase cruzeiro representam o passado e o presente; barris e fardos de palha representam o que é estranho e efêmero.

O cenário tomado pelo meio-cruzeiro sugere a ostentação de aparência sublime; as personagens paralisadas em pé sobre o barco representam a letargia coletiva; e, por fim, o motor fora da borda indica que os instrumentos para fazer Portugal retomar seu rumo e vocação existem, mas não estão sendo utilizados ou não são eficientes. A tênue esperança de transformação desse quadro histórico dá-se pela simbologia dos barris e dos fardos de palha em torno do barco, signos do que aparenta ter curta duração.

A simbologia da barca se revela também por meio das falas das personagens a seu respeito. O Arrais Contemporâneo, por exemplo, lhe lista possíveis nomes: "Vai com Deus, Barca que não sabe andar, Barca parada e Barca do motor fora da borda" (p. 15). A diversidade toponímica da barca tem em comum a carga negativa: estagnação, desgoverno, inutilidade. Tais denominações alegorizam a nação portuguesa: os que trabalham para desenvolvê-la não participam de seus benefícios; enquanto a elite que dela desfruta nenhum esforço tem empenhado: "Arrais Contemporâneo: Porque os que a impelem não vão nela e os que vão nela não a impelem" (p. 15).

Outra novidade em relação ao prototexto é a descrença nos valores cristãos, sobretudo no binômio recompensa aos bons e condenação dos maus. $\mathrm{O} A B M F B$ rechaça 
qualquer solução escatológica que sirva de lenitivo para os conflitos sociais, contrastando com os estereótipos do $A B I$, cuja condenação obriga todos a remar. Não há punição para os parasitas sociais, o que motiva a negação da realidade transcendental, conforme evidencia as falas do Arrais Contemporâneo ("Por exemplo: já ninguém acredita no Inferno (Actores vicentinos mostram grande espanto, como que assustados). E os poucos que acreditam no Paraíso, vivem como se não acreditassem nele", p. 17); e do Banqueiro ("Para o anjo: Eu já estou no Paraíso. Não posso ir para um sítio onde já estou", p. 28).

Por isso, na cena em que Simeão/Fidalgo revoltase contra a falta de função escatológica da Barca contemporânea como meio de julgamento de bons e maus, o Banqueiro altera momentaneamente o seu discurso. Ao perceber que os Actores Vicentinos levantam-se ameaçadores e avançam para o Barco, ele apresenta a figura da Igreja como instrumento apaziguador: "Esta barca leva rumo ao Céu. (Aponta para o Padre Contemporâneo). Não veem quem aqui vai? A sua presença é uma garantia" (p. 39). Nos anos 1960, segundo Paschkes, "a Igreja portuguesa foi a única instituição que conseguiu criar alguma base de apoio social ao salazarismo, garantindo a adesão e a submissão populares, tanto nas cidades quanto no campo" (PASCHKES, 1985, p. 29).

Enquanto em Gil Vicente vão à barca do inferno, indistintamente, tanto a Florença, o sapateiro artesão, o enforcado e a Brígida Vaz, quanto o fidalgo, o onzeneiro, o corregedor e o frade; em Sttau Monteiro, despojada de seu caráter metafísico, a barca torna-se símbolo da divisão de classes e da exclusão social: somente tem lugar para o Banqueiro e para seus subservientes. Apontada anteriormente pelo Arrais Contemporâneo como símbolo da exclusão social, mais uma vez ela é apresentada como figura da desigualdade, agora sob a mediação do Burguês. Representante da condição social intermediária entre o povo e o Banqueiro, ele é o responsável por manter a distância entre as classes, ao dizer ao Operário/ Parvo: "Não, não. Na nossa barca, só nós podemos estar. Trabalharás longe de nós, onde te não possamos ver" (p. 61).

Em meio à crítica contra a divisão de classes e à exploração dos operários, o Parvo surge como o único membro da sociedade portuguesa disposto aos sacrifícios necessários ao seu desenvolvimento: ele é o operário das máquinas que, irônica e simbolicamente, toma o lugar da vela, ao ser içado numa forca, tornando-se o único motor que faz a barca/nação mover-se. O espaço reservado ao Parvo, além de fora da barca/sociedade, é também o lugar que deve servir-lhe de esconderijo, à semelhança das favelas e cortiços: "Longe de nós, onde te não possamos ver" (p. 61).
O espaço oculto para onde se dirige o Parvo/ Trabalhador é também o lugar de onde procede, ao longe, o ruído de uma multidão agitada, que agora se organiza e brada palavras de ordem, como "pão" e "liberdade" (p. 62). Ainda que esteja tão distante das classes privilegiadas, a ponto de o Burguês necessitar saltar para cima da cabina do barco e [olhar] para o fundo do palco por um binóculo, o Parvo, agora convertido em Multidão, provoca o terror. Na peça, para além do medo da reação violenta do Parvo, o que mais apavora a burguesia e o patronato é o terror causado pela possível reação do povo organizado: "Burguês: (Muito preocupado): É o povo que se levantou! Industrial de Sapataria: É por causa do corte dos salários. Eu bem dizia" (p. 63).

A greve era proibida no Estado salazarista, o qual visava eliminar a luta de classes, negando a existência da dicotomia patrões e empregados, e protegendo, segundo Paschkes, os interesses superiores da nação contra os "abusos da classe trabalhadora" (PASCHKES, 1985, p. 23). Na ótica do regime, o excesso de mão de obra facilitava a repressão; por isso, ao signo sonoro que aponta para a reação dos trabalhadores - o ruído de uma multidão revoltada - o Banqueiro aciona os mecanismos estatais de repressão: "Então? Para que julgam os senhores que nós lhe pagamos? Vá depressa! Tomem as medidas que forem necessárias" (p. 63). O clímax da peça se estabelece quando, à semelhança da cena em que surge o Barco (p. 13), "muito lentamente e em contraluz", é içado o cadáver de Joane, o novo Enforcado (p. 64), cuja vida sacrificada é o único motor que move a sociedade.

O Banqueiro, dominador de todo o espaço metaforizado do palco, na qualidade de novo barqueiro e administrador do caos social instalado na sociedade, retoma o controle da situação: "foi restabelecida a ordem" (p. 64). A expressão debochada do Banqueiro pode ser associada ao mote repetido pelo então ministro António Salazar, quando se referia a seu programa de reorganização da vida nacional, de 1934, com o qual justificava a manutenção da ditadura: "Quando a ditadura nacional tomou conta do Governo, de muitos sectores lhe assinalaram como única finalidade: 'arrumar a casa', 'acabar a desordem', 'manter a casa arrumada" (SARAIVA, 1998, p. 524).

A cena do Parvo/Trabalhador/Enforcado sugere o status quo excludente que Sttau Monteiro pretende denunciar em sua peça, na qual o motor fora da borda é signo teatral da força popular que movimenta a sociedade portuguesa, não obstante excluída da participação de seus benefícios. Os demais personagens, sentados no barco, tendo seus corpos sustentados não pelas forças de suas próprias pernas, mas sobre o barco/nação que os mantém, permanecem estagnados: "ouve-se o ruído do trabalhar dum motor fora da borda. A luz começa a diminuir de 
intensidade muito gradualmente, com os actores hirtos como cadáveres, em posições de pose heroica, sentados no barco" (p. 64-65).

O ruído é o signo sonoro comum às duas cenas, intensificadas por dois signos de signos: o ruído de uma multidão revoltada e o ruído de um motor fora da borda. Assim, da mesma forma como o Burguês lança mão do binóculo para enxergar a imagem da realidade que lhe chega somente pelos signos sonoros, também o público é induzido a converter os ruídos em imagem construída no interior de sua própria consciência. O efeito é eficiente se considerarmos que o público identificado pelo Arrais Vicentino é de "moços fidalgos ou que diabos sejam" (p. 65), ou seja, de burgueses.

\section{Pranchas e escadas: na borda da barca, à margem da sociedade}

O Dicionário de símbolos registra que "pontes e similares representam a passagem de uma margem à outra, do estado humano aos estados supra-humanos, do mundo sensível ao mundo suprassensível" (CHEVALIER \& GHEERBRANT, 2000, p. 729). Em o $A B I$, o Anjo impede o acesso à prancha que levaria à Barca da Glória o Fidalgo, o Sapateiro, e Brízida Vaz; enquanto o Diabo oferece-a indistintamente, como para Brízida Vaz ("Hou barqueiro da ma ora,/ponde a prancha, que eis me vou", p. 237); e para o Corregedor ("Que fazes tu, barzoneiro?/faze-lhe essa prancha prestes", p. 240). A prancha simboliza, portanto, o tratamento igualitário que o Diabo dispensa a todos os representantes da sociedade portuguesa, ainda que para a condenação.

Em o $A B M F B$, o ingresso no barco moderno exige uma escada. Por ela, o Arrais Contemporâneo ao mesmo tempo em que acessa no meio-cruzeiro, estabelece também a distância entre o presente por ele simbolizado e o passado representado pelos atores vicentinos, os quais são detidos com um gesto, sob a alegação de que tanto os representantes do passado quanto os espectadores do presente não a reconheceriam. A prancha, então, torna-se signo da separação entre os incluídos e os excluídos.

A partir desse ponto, há um trânsito intenso, quer dos personagens vicentinos, quer dos contemporâneos, ora subindo ora descendo da barca, dando uma enganosa impressão de haver, em Portugal, a comunhão entre passado e presente ou o câmbio entre classes sociais. As rubricas registram essa movimentação: "correm para o barco, mas o Arrais Contemporâneo chega primeiro [à escada] e detém-nos" (p. 16); "os actores vicentinos riemse do aspecto do ator contemporâneo que sobe a escada" (p. 18); "Arrais Contemporâneo: Alto! (Sobe ao barco.) O nosso auto não é igual ao que vocês representavam antigamente" (p. 20).
A representação ideológica da escada, em o $A B M F B$, somente será retomada na última cena. Enquanto os espectadores assistem ao domínio do Banqueiro sobre a barca e seus ocupantes, os soldados marcham para a barca e começam a subir a escada que lhes dá acesso (p. 69). Trata-se da intervenção militar coordenada pelo Diabo/Banqueiro, objetivando estabelecer a ordem que lhe interessa impor à barca/sociedade.

Em Sttau Monteiro, o pessimismo é evidente: há uma moderna barca, mas cujo motor fora da borda não a leva "nem a Nice, nem ao Céu, nem ao Inferno", tornando-se uma alegoria satírica ao desgoverno português dos 1960, e a consequente estagnação do país, como atestam as palavras finais do Arrais Vicentino: “... Barca sem rumo, onde irá parar? Comprar nela passagem? Outro que não eu! Este batel já daqui não sai... Barca parada não serve para navegar" (p. 69).

O tema principal do intertexto de Sttau Monteiro é a ausência de inclusão social e, não obstante os atores de $A B M F B$ acompanharem as personagens do século XVI que eles representam, também os atores das peças vicentinas são retomados com o objetivo de refletir sua condição social inferior. $\mathrm{O}$ artifício visa manter o espectador consciente do que se passa no plano ficcional, a fim de conferir ao espetáculo um caráter racional até mesmo da própria condição do ator junto à sociedade perante a qual atua. Um caso ilustrativo é o Arrais Vicentino, que se desdobra na personagem-ator Amâncio Toutinegra: na qualidade de Arrais Vicentino ele se apresenta aos contemporâneos como o ator-real: "Ator, ladrão, feirante e má rês... Em vida, como ator, fui Arrais das barcas de mestre Gil representado o auto, misturava-me com os senhores do paço e exercia a minha profissão de ladrão" (p. 52-53).

Nesta cena, a quebra da quarta parede produz o efeito anti-ilusionista, cujo proposito principal é manter no espectador um determinado "afastamento" que lhe possibilite racionar a respeito da própria condição do artista que ele vê no palco em relação à personagem que ele representa. O recurso revela os procedimentos estéticos e o caráter crítico da peça por trás dos mecanismos paródicos intertextuais ali empregados. Daí a preocupação em fazer, desde a primeira rubrica, com que personagens e atores, igualmente distinguidos, dirijam-se ao público: "Surgem respectivamente pela esquerda e pela direita do palco, um homem em traje contemporâneo e outro em traje Vicentino que correm para o centro, estacam junto à ribalta e falam para o público" (p. 11).

\section{E a que porto chegamos}

O conceito de tempo relativo desenvolvido pela teoria bakhtiniana do cronotopos guia Sttau Monteiro para uma nova perspectiva histórica que lhe propicia tecer uma 
aguda crítica à sociedade do século XX, já que o tratamento histórico é norteado pelo desejo de transformação. Por isso, longe de forjar distorcidos modelos extraídos da História de Portugal para se enquadrarem no projeto de retomada do tempo de enriquecimento econômico e artístico, Monteiro compreende a necessidade de eliminação do principal elemento responsável pela exploração da sociedade portuguesa representada na Barca: o Onzeneiro/Banqueiro. Para ele, não é suficiente resgatar tempos de prosperidade; urge, segundo sua intenção ideológica, expurgar a estrutura de exclusão e injustiça: o capitalismo financeiro.

Em Gil Vicente, o inimigo está associado a elementos religiosos que podem expurgar a injustiça e depurar a sociedade, por meio do julgamento promovido pelo Anjo e pelo Diabo. Em Monteiro, no entanto, o inimigo singular é o capitalismo selvagem protagonizado pelo Banqueiro/ Onzeneiro, cuja ação exploradora ofusca a ação diabólica do Arrais Vicentino. O $A B M F B$ é uma estilização teatral calcada em um pessimismo crasso no perfil da chamada Geração de 60 a que pertenceu o autor; por isso, longe de propor um projeto utópico para a nação, pauta-se por uma denúncia maior: na barca comandada pela ditadura salazarista, os que a impelem (povo) não vão nela (sociedade) e os [privilegiados] que vão nela não a impelem.

\section{Referências}

BAKHTIN, Mikhail. Estética da criação verbal. Trad. do francês: Maria E. G. G. Pereira. São Paulo: Martins Fontes, 1997.
BAKHTIN, Mikhail. Problemas da poética de Dostoiévski. Trad. Paulo Bezerra. Rio de Janeiro: Forense Universitária, $1997 b$.

BAKHTIN, Mikhail. Questões de literatura e estética: a teoria do romance. Trad. Aurora Fornono Bernadini et al. São Paulo: Editora Hucitec /Editora Unesp, 1998.

BERNARDES, José Augusto Cardoso. Sátira e lirismo: modelos de síntese no Teatro de Gil Vicente. Coimbra: Acta Universitatis Conimbrigensis, 1996.

CHEVALIER, Jean; GHEERBRANT, Alain. Dicionário de símbolos. Trad. Vera Ada Costa e Silva et al. Rio de Janeiro: José Olímpio, 2000.

MACHADO, Irene A. O romance e a voz: a prosaica dialógica de M. Bakhtin. Rio de Janeiro: Imago; São Paulo: FAPESP, 1995.

MONTEIRO, Luís de Sttau. Auto da barca do motor fora da barca. Lisboa: Ática, 1970.

PASCHKES, Maria Luísa Nabinger de Almeida. A ditadura salazarista. São Paulo: Brasiliense, 1985.

SARAIVA, José Hermano. História de Portugal. Lisboa: Europa-América, 1998.

VENDRAMINI, José Eduardo. O teatro de Luís de Sttau Monteiro: do enigma ao panfleto. 1978. 236 f. Tese (Doutorado em Letras) - Faculdade de Filosofia, Letras e Ciências Humanas, USP, 1978.

VICENTE, Gil. Obras de Gil Vicente. Porto: Lello \& Irmãos Editores, 1965.

Recebido: 18 de outubro de 2015 Aprovado: 22 de dezembro de 2015 Contato: jsantann@hotmail.com 